\title{
HR Wallingford
}

\section{Buoyancy considerations for integrated discharges}

Wood, M.J., Mead, C.T. and Wild, B.R.

Reproduced from a paper presented at:

6th International Symposium on Environmental Hydraulics Athens, Greece

23-25 June 2010 


\title{
BUOYANCY CONSIDERATIONS FOR INTEGRATED DISCHARGES
}

\author{
Wood, M.J., Mead, C.T. and Wild, B.R.
}

HR Wallingford Ltd, United Kingdom

\begin{abstract}
Marine discharges are either positively-, negatively- or neutrally-buoyant, depending on factors such as discharge temperature and salinity in relation to those of the ambient receiving waters. When planning marine discharges, appropriate assessment of the dispersion and dilution of the effluent is important for both environmental and engineering reasons. HR Wallingford has wide experience of such assessments for all types of marine discharge. In cases of either strong positive or strong negative discharge buoyancy, the density is usually dominated by either a high temperature or high salinity, with the other parameter at a similar level to that of the receiving water. In such cases, assessment is relatively straightforward. Combined facilities, such as integrated power and water plants, are in increasing use worldwide. Discharges from such facilities are typically both significantly warmer and more saline than the receiving waters, which often results in marginal positive or negative buoyancy. This can complicate assessment in several ways, which are examined in this paper. Modelling techniques are recommended that can represent satisfactorily, for example, discharges of varying buoyancy from given locations, and plumes that change from positive to negative buoyancy during the far-field dispersion phase. The relevant issues are considered with reference to recent computational modelling studies undertaken at HR Wallingford.
\end{abstract}

\section{Introduction}

Marine discharges are either positively-, negatively- or neutrally-buoyant, depending on factors such as temperature or the concentration of constituents within the discharge in relation to those of the ambient receiving waters. In simple terms, discharges of positive buoyancy tend to form layers at the sea surface whilst negatively-buoyant (or dense) discharges tend to sink towards the sea bed. The two types of behaviour are shown in Figure 1. Neutrally-buoyant discharges tend to mix relatively rapidly through the water depth. When planning marine discharges, accu-rate and appropriate assessment of the dispersion and dilution of the effluent is important for various reasons; environmental impact must be considered, as must engineering constraints, such as the need to limit recirculation to seawater intakes.

HR Wallingford has wide experience of the assessment of discharge dispersion and dilution for all types of marine discharge. Positively-buoyant discharges include warm cooling water discharges from power stations, and freshwater discharges from wastewater treatment plants. Negatively-buoyant discharges include saline discharges from desalination plants, cold discharges from Liquefied Natural Gas (LNG) regasification facilities, typical produced water from oil and gas operations, and brine from salt cavern leaching operations. In these cases, either the temperature or the salinity of the discharge is usually similar to that of the receiving water, so that the buoyancy of the resulting plume is dominated by the excess of the other parameter. In such cases, discharge dispersion assessment is relatively straightforward (see, for example, Wood \& Mead (2008) and Bleninger et al. (in press)). 


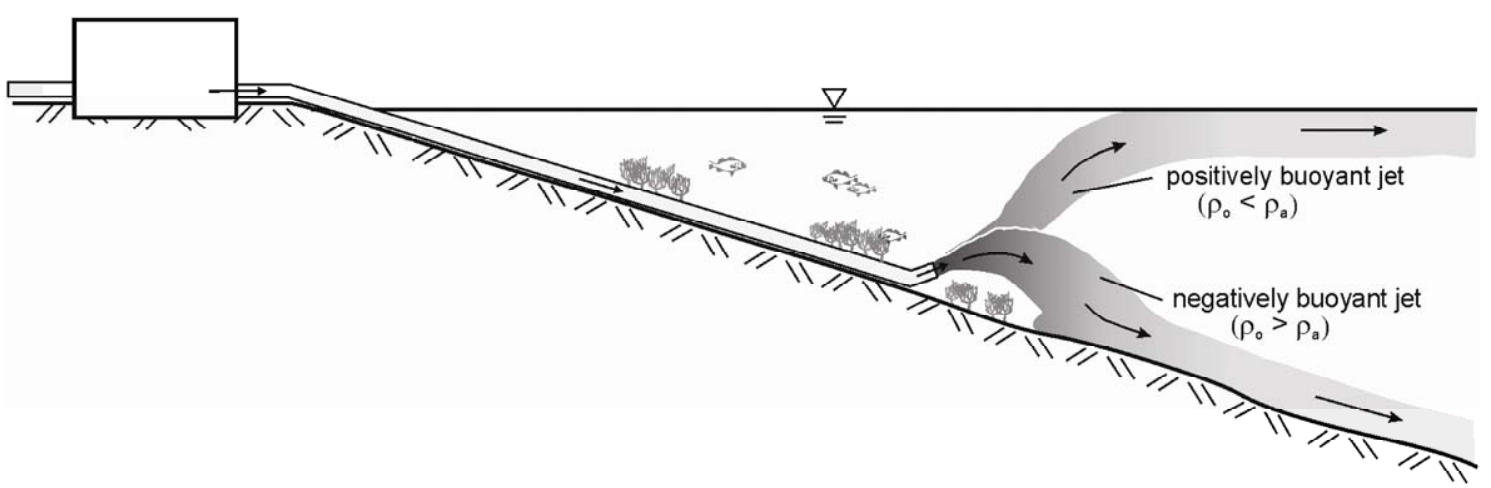

Figure 1 Classical positively- and negatively-buoyant plume behaviour (adapted from Bleninger et al. (in press))

Combined facilities, such as integrated power and desalination plants, are in increasing use around the world, and particularly in the Middle East. Discharges from such facilities are typically both significantly warmer and more saline than the waters which receive them. Historically, such combined discharges have been strongly positively-buoyant, as the volume of cooling water has been much greater than the volume of highly-saline effluent from the desalination plant. However, due to recent changes in desalination technology, notably the increased use of reverse osmosis (RO) plants in preference to multi-stage flash (MSF) technology, desalination plant yield has increased, with a corresponding increase in the concentration of the high salinity waste product. Also, whereas the MSF process involves the heating of the feed water, the RO process does not, so the increased salinity of the discharge combined with a reduction in the relative volume of cooling water often results in combined discharges that are now only marginally positively-buoyant or, in some cases, marginally negatively-buoyant (that is, their densities are similar to those of the ambient receiving waters). In HR Wallingford's experience, there are three ways in which this can affect discharge dispersion assessment:

- $\quad$ Plumes that are marginally positively-buoyant at their points of discharge can increase in density after discharge, due to atmospheric cooling. This can lead to reversals of buoyancy, such that positively-buoyant plumes become negatively-buoyant.

- $\quad$ Plumes that are positively-buoyant during times of high power output or low desalinated wa-ter production rate can become negatively-buoyant during times of lower power output or higher desalination production rate.

- Plumes from particular outfalls can be either positively-buoyant or negatively-buoyant, depending on seasonal fluctuations in the ambient seawater temperature.

Reversal of plume buoyancy has been considered in detail by Zhang and Baddour (1997), who consider the effects of non-linear buoyancy dependency on thermal-saline plumes. The ef-fects observed by the present authors relate to changes and reversals in buoyancy due to atmos-pheric, environmental and operational causes, and are demonstrated in Section 3 with reference to recent computational modelling studies undertaken at HR Wallingford for naturally unstrati-fied environments. This paper is intended to serve as a reminder that such issues should be considered in modelling studies, in view of the plume buoyancy reversals associated with the increasing development of combined facilities. 


\section{The form of seawater density curves}

Knowledge of the non-linear variation of seawater density with temperature and salinity is key to understanding the phenomena described in Section 3. Several authors have considered this relationship; the general form of the seawater density curves is presented, for example, in Figure A.1 of Fischer et al. (1979). In simple terms, as is generally known, density increases as salinity increases, and reduces as temperature increases. In addition, for a given salinity, the density decreases more sharply with temperature at higher temperatures, which means that smaller changes in temperature are required to effect significant density changes. As noted by Fischer et al., most seawater falls within a narrow range of salinity. Therefore, in general, warmer ambient seawater temperatures during summer months mean lower ambient densities, and the potential for larger density changes with smaller variations in temperature.

\section{Site examples}

\subsection{Effects of atmospheric cooling on plumes of marginal buoyancy}

As described in Section 1, discharge plumes that are both warmer and more saline than the receiving water are often marginally positively-buoyant on release. Following release into the receiving waters, they tend to rise towards the water surface. Initially, mixing and dilution of the discharge is governed by several factors, including turbulent mixing within the initial jet, and shear-induced mixing. Once the plume reaches the surface, heat energy within the discharge can dissipate to the atmosphere, through atmospheric cooling. The rate of heat flux at the air-water interface is affected by several factors, including the air temperature, evaporation rate and wind speed, and has been the subject of several studies (see, for example, Sweers (1976), Ryan et al. (1974)).

The dissipation of heat to the atmosphere can mean that the plume cools significantly before the excess salinity has been diluted by turbulence to near-ambient values. For marginally buoy-ant discharges with sufficiently high salinity, this can result in the excess salinity eventually dominating the buoyancy, so that the buoyancy reverses from marginally positive to marginally negative. This causes higher plume concentrations near the sea bed, with potentially a warmer and more saline layer forming below a cooler and less saline layer above. An example of this behaviour is shown in Figure 2, which shows a vertical cross-section of excess temperature through a warm, saline plume, with excess temperatures profiles at the sea surface and sea bed along the section. In the cross-section, a scale factor of 100:1 has been applied to the vertical axis for clarity.

In Figure 2 in the immediate vicinity of the outfall, the excess temperature is highest in the lower water column, as the outfall is located at the sea bed. As the initially buoyant plume rises to the sea surface, a short distance away from the outfall the temperature is stably stratified, with a warm plume layer above cooler ambient water. As the excess temperature and salinity are reduced through mixing of the discharge, the plume becomes neutrally-buoyant, with excess temperature approximately evenly-distributed through the water column. In Figure 2 this can be seen between approximately $1 \mathrm{~km}$ and $3.5 \mathrm{~km}$ downstream of the outfall. Eventually, as the cooling to the atmosphere reduces temperature at the sea surface, the salinity dominates the buoyancy, and a region is formed with a warmer and more saline layer below cooler and less saline water. This behaviour could have implications for engineering design, where the goal might be to reduce the temperature of water abstracted at a near-bed intake. Any model used in the analysis of such a plume should ensure that atmospheric fluxes are taken into account, and that the model can suitably resolve temperature variations through the water column, including the nearbed region. This may not be immediately obvious to the modeller expecting to focus computational effort wholly near the sea surface. 


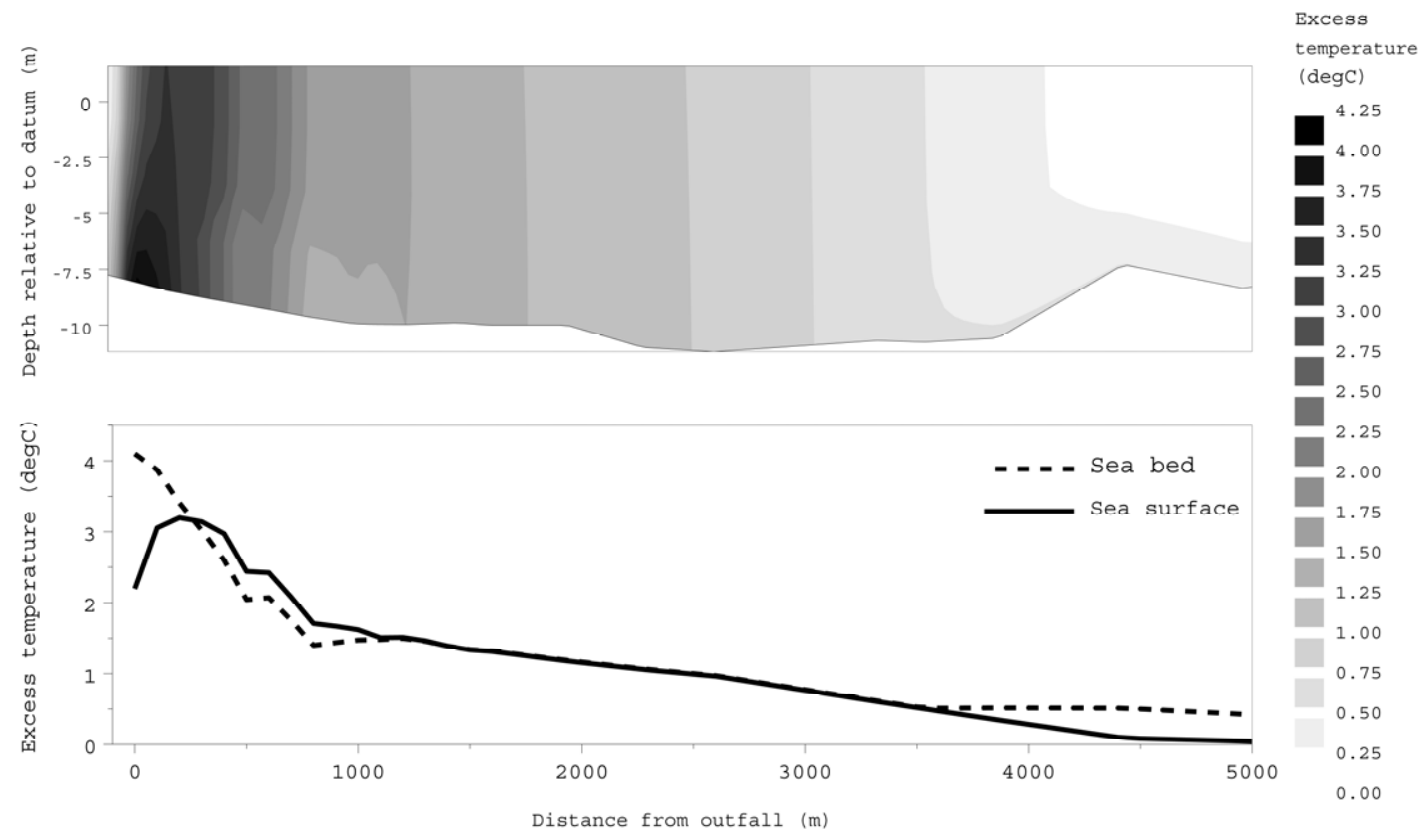

Figure 2 Vertical cross-section of excess temperature through a plume of reversing buoyancy

\subsection{Buoyancy variations during the course of normal facility operations}

The operating conditions of some facilities mean that the buoyancy of their discharges can either be positive, negative, or marginal, depending on the operating scenario. One such example is combined power and water plants, where power generation begins before the desalination process is started. This means that for some time the discharge will consist of positively-buoyant cooling water, and some time later, when the permeate is produced, the discharge buoyancy may change to marginally positive or even marginally negative. In other cases, the same outfall can be used for temporary discharges of entirely different effluents. This can hap-pen for industrial discharges of produced water, where an initial so-called "hydrotest" is carried out before the main discharge commences. The hydrotest cocktail is often positively-buoyant, whilst the main produced water discharge is negatively-buoyant. Assessments used to support Environmental Impact Assessments for such discharges must therefore use mixing and disper-sion models that can simulate both types of discharge.

\subsection{Seasonal variations in buoyancy}

Several factors can cause buoyancy variations through the year. As described in Section 2, warmer ambient seawater temperatures during summer months mean lower ambient densities A discharge that is marginally positively-buoyant in summer may become marginally negativelybuoyant in winter, as a given temperature contrast between the discharge and ambient seawater has a more pronounced effect on density at higher temperatures.

The above behaviour is only possible when the make-up of the effluent remains seasonally invariant. Other seasonal factors may affect the issue; power demand generally varies with season. In the Middle East, for example, the requirements for air conditioning are high during summer months, whereas water demand is more uniform through the year (see, for example, Al Zayer \& Al Ibrahim (1996), or Al Shareef et al. (2008)). This means that discharges from combined power and water facilities are likely to be more buoyant in summer than winter, due to the increased volume of cooling water within the discharge. This is accentuated by the 
sharper changes in density with temperature at higher summer temperatures, as described in Section 2.

Similar density variations might also occur for District Cooling plants, which provide central air-conditioning to buildings and industrial areas. In a District Cooling system, water is piped to, and circulated around, buildings where it absorbs thermal energy. The resulting warm water is then discharged back to sea (although the volumes involved are much smaller than typical power station cooling water discharges). In some cases, water is lost through evaporation prior to discharge, and this means that as well as elevated temperature, the discharge may also have elevated salinity relative to the ambient seawater. The volume of cooling water, its excess temperature/salinity and, therefore, its density, can all vary with seasonal demand.

Another factor that should be considered is the variation in atmospheric cooling during the year. During summer months, the warmer air temperatures encourage more cooling due to evaporation, which means that phenomena such as the reversing plume buoyancy described in Section 3.1 can be enhanced. Similar enhancement would likely be observed during periods of relatively strong wind, where cooling effects are increased, as demonstrated in Jirka et al. (1975), which shows the variation of the heat exchange coefficient with wind speed and seawater temperature.

Assessments of mixing and dispersion should take into account the likelihood of any seasonal variations in plume constituents and behaviour.

\section{Summary}

Most studies of the dispersion and dilution of marine discharges deal with plumes that are either positively-buoyant or negatively-buoyant. This paper has discussed some of the issues that can arise when dealing with marine discharges that fall between the two classes so as to have marginal or reversing buoyancy. For such discharges, it is concluded to be essential to ensure that dispersion modelling techniques are applied that can represent satisfactorily discharges of different buoyancy from given locations, and plumes that change from positive to negative buoyancy during whilst dispersing in the sea. For example, in situations where plume buoyancy changes from positive to negative, it is important to apply adequate model vertical resolution in both the upper and lower water column. It is vital that atmospheric fluxes, relevant meteorological effects and seasonal variations are all considered as part of any detailed assessment.

The examples considered in this paper, and other recent HR Wallingford studies, support the assertion of Zhang and Baddour (1997) that more complicated models may be required to allow for the non-linear buoyancy dependency of temperature and salinity within thermal-saline discharges. Such processes are not typically included in the current generation of computational models.

\section{References}

Al-Shareef, A.J., Mohamed, E.A. and Al-Judaibi, E. 2008. Next 24-Hours Load Forecasting Using Artifi-cial Neural Network (ANN) for the Western Area of Saudi Arabia, J. King Abdulaziz University: Eng. Sci., 19 (2): 25-40.

Al-Zayer, J. and Al-Ibrahim, A.A. 1996. Modelling the impact of temperature on electricity consumption in the Eastern Province of Saudi Arabia, J. Forecasting, 15 (2): 97-106.

Bleninger, T., Niepelt, A. and Jirka, G.H. In press. Desalination Plant Discharge Calculator, Desalination, accepted, 2009. 
Fischer, H.B., List, E.J., Koh, R.C.Y., Imberger, J. and Brooks, N.H. 1979. Mixing in inland and coastal waters, Academic Press, New York.

Jirka, G.H., Ryan, P.J. and Stolzenbach, K.O. 1975. Basic physical processes in heat transport. In Euro-pean Course on Heat Disposal from Power Generation in the Water Environment; Lecture Notes, 2327 June 1975. Delft Hydraulic Laboratory, Delft, 4-1 - 4-129.

Ryan, P., Harleman, D.R.F. and Stolzenbach, K.D. 1974. Surface Heat Loss from Cooling Ponds. Water Resources Res., 10 (5): 930-938.

Sweers, H.E. 1976. A nomogram to estimate the heat-exchange coefficient at the air-water interface as a function of wind speed and temperature; a critical survey of some literature. J. Hydrol., 30: 375-401.

Wood, M. J. and Mead, C. T. 2008. Dense Jet Assessment Procedure. Proc. 5th International Conference on Marine Waste Water Discharges and Coastal Environment, Cavtat, Croatia, 2731 October 2008.

Zhang. H. and Baddour, R. E., 1997. Thermal-saline jets with reversing buoyancy. Proc. 27th IAHR Con-gress on Environmental and Coastal Hydraulics: Protecting the Aquatic Habitat, San Francisco, CA, 10-15 August 1997. 


\title{
Fluid thinking...smart solutions
}

HR Wallingford provides world-leading analysis, advice and support in engineering and environmental hydraulics, and in the management of water and the water environment. Created as the Hydraulics Research Station of the UK Government in 1947, the Company became a private entity in 1982, and has since operated as a independent, non profit distributing firm committed to building knowledge and solving problems, expertly and appropriately.

Today, HR Wallingford has a 50 year track record of achievement in applied research and consultancy, and a unique mix of know-how, assets and facilities, including state of the art physical modelling laboratories, a full range of computational modelling tools, and above all, expert staff with world-renowned skills and experience.

The Company has a pedigree of excellence and a tradition of innovation, which it sustains by re-investing profits from operations into programmes of strategic research and development designed to keep it - and its clients and partners - at the leading edge.

Headquartered in the UK, HR Wallingford reaches clients and partners globally through a network of offices, agents and alliances around the world.

\section{HR Wallingford}

Working with water

\author{
HR Wallingford Ltd \\ Howbery Park \\ Wallingford \\ 0xfordshire 0X10 8BA \\ UK \\ $\begin{array}{ll}\text { tel } & +44(0) 1491835381 \\ \text { fax } & +44(0) 1491832233 \\ \text { email } & \text { info@hrwallingford.co.uk }\end{array}$
}

www.hrwallingford.co.uk 